\title{
RESULTADOS DE ESTUDOS BRASILEIROS DE 1996-2016 SOBRE ATITUDES DE ESTUDANTES EM RELAÇÃO À MATEMÁTICA ${ }^{1}$
}

\author{
RESULTS OF 1996-2016 BRAZILIAN STUDIES ON STUDENT ATTITUDES \\ TOWARDS MATHEMATICS
}

DOI: 10.23926/RPD.2526-2149.2020.v5.n3.p1547-1567.id857

\section{Renata Cristina Alves Matni \\ Mestre em Educação pela \\ Universidade do Estado do \\ Pará (UEPA) \\ renata_matni@hotmail.com}

\section{Pedro Franco de Sá}

Doutor em Educação

(UFRN)

Professor Titular de

Educação Matemática do

Departamento de

Matemática, Estatística e

Informática (UEPA)

pedro.franco.sa@gmail.com

\section{Maria de Lourdes \\ Silva Santos}

Doutora em Educação (PUC-

Rio)

Professora Adjunta do

Departamento de Educação

Geral e do Mestrado

Profissional em Ensino de

Matemática (UEPA)

2011malu.melo@gmail.com
Resumo: Este trabalho apresenta os resultados de uma pesquisa que objetivou obter informações sobre as atitudes de estudantes em relação à Matemática a partir de estudos já realizados do período 1996-2016. As informações foram obtidas a partir da análise de trabalhos brasileiros sobre atitudes em relação à Matemática. Foram analisados trabalhos de Educação e Educação Matemática, em um total de 18 estudos. A análise dos trabalhos indicou que quando os estudantes compreendem o assunto, desenvolvem autoestima e tem um convívio saudável com o professor, a maior parte apresenta atitudes favoráveis em relação à disciplina. Concluiu-se que dos estudantes que participaram das pesquisas analisadas a maioria apresentou predominância de sentimento positivo em relação à Matemática, contrariando o senso comum sobre o tema, e que as atitudes negativas aumentam de frequência com o avanço da escolaridade e idade.

Palavras-chave: Educação Matemática. Atitudes em Relação à Matemática. Sentimento em Relação à Matemática.

\begin{abstract}
This work presents the results of a research that aimed to obtain information about the students' attitudes towards Mathematics from studies already carried out from 1996-2016. The information was obtained from the analysis of Brazilian works on attitudes towards Mathematics. Mathematics Education and Education works were analyzed, in a total of 18 studies. The analysis of the works indicated that when students understand the subject, develop selfesteem and have a healthy relationship with the teacher, most of them present favorable attitudes towards the discipline. It was concluded that of the students who participated in the researches analyzed, the majority had a predominance of positive feelings in relation to Mathematics, contrary to common sense on the subject, and that negative attitudes increase in frequency with the advance of schooling and age.
\end{abstract}

Keywords: Mathematical Education. Attitudes in relation to Mathematics. Feelings in relation on Mathematics.

\footnotetext{
${ }^{1}$ Pesquisa realizada com o apoio financeiro da Fundação Amazônia de Amparo a Estudos e Pesquisas FAPESPA/CAPES.
} 


\title{
1 INTRODUÇÃO
}

Na contemporaneidade é muito comum ouvirmos afirmações por parte dos estudantes da educação básica e superior sobre o gostar ou não da disciplina Matemática. Com base em nossas experiências, a primeira impressão que se tem é de que a maioria dos estudantes não gosta da mesma.

\begin{abstract}
Participando de congressos e encontros de Educação Matemática, de bancas de dissertações e teses ou ainda assistindo a seminários e palestras ouve-se, com frequência, a afirmação de que os alunos não gostam de Matemática. A ideia veiculada é que os alunos não gostam da Matemática "per se". Porém, não são tratados outros vários aspectos componentes do ensino-aprendizagem de Matemática. (BRITO, 1996, p. 02)
\end{abstract}

A citação de Brito (1996) corrobora com as nossas experiências em sala de aula sobre o gostar dos estudantes em relação à disciplina mencionada. Além disso, de acordo com Lopes (2008 apud SILVA, 2016) a Matemática apresenta uma preconcepção histórica errada por ser considerada uma disciplina que não é compreendida por todos. Isto justifica que a reflexão sobre o ensino e aprendizagem da Matemática na educação básica é necessária, pois quando a mesma é ensinada de maneira "mecânica", ou seja, apenas por meio de algoritmos, sem que o aluno reflita sobre as resoluções, pode fazer com que ele não perceba os significados dos problemas, o que o leva a considerar a disciplina como a mais difícil de ser compreendida, enraizando essa concepção e a reproduzindo dentro e fora da vida escolar.

Os Parâmetros Curriculares Nacionais (PCN) de Matemática indicam a importância de ampliar a construção de significados e fazer o aluno buscar estratégias, tanto pessoais, como convencionais para resolver problemas. E, também, ressaltam a relevância:

[...] de o aluno desenvolver atitudes de segurança com relação à própria capacidade de construir conhecimentos matemáticos, de cultivar a auto-estima, de respeitar o trabalho dos colegas e de perseverar na busca de soluções. Adotam como critérios para seleção dos conteúdos sua relevância social e sua contribuição para o desenvolvimento intelectual do aluno, em cada ciclo. (BRASIL, 1998, p.15)

Pesquisas sobre atitudes em relação à Matemática tem um volume considerável de trabalhos que procuram identificar e comparar alguns fatores associados às atitudes positivas ou negativas de alunos da educação básica e ensino superior frente à disciplina e aos conteúdos trabalhados na mesma. Nas investigações foram utilizados instrumentos como uma escala de atitudes, fatores esses que influenciam no processo de ensino e aprendizagem. Entre esses, podemos citar Brito (1996), Araújo (1999), Utsumi (2000) e Brito, Faria e Moro (2008).

Brito (1996) registra que há uma crença de que a Matemática é considerada a disciplina mais difícil de ser aprendida, na qual os alunos apresentam "aversão" e diversas dificuldades, 
consequentemente, produzindo bloqueios que muitos mostram por sentirem-se incapacitados de entender e por já terem opiniões formadas a respeito da disciplina.

Para o presente trabalho será utilizada a definição de Brito (1996) sobre o que é atitude, a qual diz que seria a forma de cada pessoa agir em determinadas situações:

[...] definida como uma disposição pessoal, idiossincrática, presente em todos os indivíduos, dirigida a objetos, eventos ou pessoas, que assume diferente direção e intensidade de acordo com as experiências do indivíduo. Além disso, apresenta componentes do domínio afetivo, cognitivo e motor. (p. 11)

Dessa forma, este artigo apresenta os resultados de uma revisão de estudos sobre atitudes em relação à Matemática com a finalidade de responder a seguinte questão: Que resultados costumam ser apresentados em trabalhos científicos que tratam de atitudes (favoráveis ou não) de estudantes em relação à disciplina Matemática?

Diante do exposto, este trabalho apresenta os resultados de uma pesquisa que objetivou analisar estudos brasileiros do período 1996-2016 sobre atitudes de estudantes em relação à matemática, verificando o comportamento e sentimento dos discentes em relação à disciplina, respondendo à questão acima.

\section{Metodologia}

A pesquisa foi desenvolvida por meio das seguintes etapas: levantamento, seleção, estudo, escolha, análise, categorização e análise por categoria.

O levantamento ocorreu por meio de busca no Google Acadêmico, repositórios da Universidade Estadual de Campinas (UNICAMP) e site de anais de eventos nacionais e periódicos, considerando trabalhos publicados no período que compreende 1996 a 2016, contemplamos tal período devido termos nos baseado na definição de Brito (1996) sobre atitudes e também, porque o ano de 2016 foi o qual realizamos nossa pesquisa bibliográfica. A procura se deu com base nas seguintes palavras-chave: trabalhos relacionados às atitudes em Matemática; trabalhos relacionados às atitudes em números e operações; trabalhos relacionados às atitudes em espaço e forma; trabalhos relacionados às atitudes em tratamento da informação. Como resultados do levantamento foram encontrados 71 trabalhos.

A seleção foi realizada por meio dos seguintes critérios:

1) Os trabalhos deveriam ser na forma de artigo, publicado em anais ou periódicos, dissertações ou teses;

2) Nos trabalhos deveriam ter sido realizadas pesquisa de campo;

3) Os trabalhos deveriam conter apresentação de forma explícita dos resultados. 
Após a seleção o total de trabalhos acolhidos foi de dezoito, sendo quatro teses e uma dissertação na área da educação e treze artigos.

O estudo ocorreu da seguinte forma: cada um dos trabalhos selecionados foi analisado buscando as informações a seguir: objetivo, questão de pesquisa, descrição da metodologia adotada, resultados obtidos, análise dos resultados e conclusões/ sugestões.

Após o estudo dos trabalhos selecionados realizamos uma categorização dos mesmos. Isso foi possível a partir das semelhanças observadas nas investigações, em que organizamos os trabalhos nas categorias a seguir, que nortearam a estrutura deste texto nessa ordem: (1) estudos sobre atitudes em relação à Matemática de um modo geral; (2) estudos sobre atitudes no bloco número e operações; (3) estudos sobre atitudes no bloco espaço e forma; (4) estudos sobre atitudes no bloco tratamento da informação. O Quadro 1 mostra os estudos que elencamos por categoria.

Quadro 1 - Categoria dos estudos sobre atitudes em relação à Matemática

\begin{tabular}{|c|c|c|c|c|}
\hline Categoria & Autor (es) & Ano & Título do trabalho & Tipo de trabalho \\
\hline \multirow{8}{*}{$\begin{array}{l}\text { Atitudes em } \\
\text { relação à } \\
\text { Matemática } \\
\text { de um modo } \\
\text { geral }\end{array}$} & Brito & 1996 & $\begin{array}{l}\text { Um estudo sobre as atitudes } \\
\text { em relação à Matemática em } \\
\text { estudantes de } 1^{\circ} \text { e } 2^{\circ} \text { graus }\end{array}$ & Tese de livre docência \\
\hline & Araújo & 1999 & $\begin{array}{c}\text { Influências das habilidades e } \\
\text { das atitudes em relação à } \\
\text { Matemática e a escolha } \\
\text { profissional }\end{array}$ & Tese \\
\hline & $\begin{array}{c}\text { Ferreira e } \\
\text { Wodewotzki }\end{array}$ & 2007 & $\begin{array}{l}\text { Matemática e escala de } \\
\text { atitudes no ensino médio: uma } \\
\text { abordagem no contexto da } \\
\text { pesquisa qualitativa }\end{array}$ & Artigo \\
\hline & Brito, Faria e Moro & 2008 & $\begin{array}{c}\text { Atitudes de professores e } \\
\text { futuros professores em relação } \\
\text { à Matemática }\end{array}$ & Artigo \\
\hline & Ferreira e Torisu & 2009 & $\begin{array}{l}\text { Atitudes e autoconceito em } \\
\text { relação à Matemática: um } \\
\text { estudo com alunos do } 5^{\circ} \text { e do } \\
7^{\circ} \text { ano das escolas públicas de } \\
\text { Ouro Branco - MG }\end{array}$ & Artigo \\
\hline & $\begin{array}{c}\text { Descovi, Marmitt e } \\
\text { Soares }\end{array}$ & 2010 & $\begin{array}{l}\text { Concepções e atitudes em } \\
\text { relação à Matemática: prática } \\
\text { em busca de uma construção } \\
\text { positiva }\end{array}$ & Artigo \\
\hline & Jesus e Tacacima & 2012 & $\begin{array}{c}\text { As atitudes em relação à } \\
\text { Matemática e o desempenho } \\
\text { em cálculo diferencial e } \\
\text { integral de alunos de } \\
\text { Engenharia }\end{array}$ & Artigo \\
\hline & Costa e Costa & 2013 & $\begin{array}{l}\text { Desempenho e atitudes em } \\
\text { relação à matemática de alunos } \\
\text { do } 6^{\circ} \text { ano do ensino } \\
\text { fundamental }\end{array}$ & Artigo \\
\hline
\end{tabular}




\begin{tabular}{|c|c|c|c|c|}
\hline & Jesus e Testani & 2016 & $\begin{array}{c}\text { As atitudes em relação à } \\
\text { Matemática e o desempenho } \\
\text { em cálculo diferencial e } \\
\text { integral na variável complexa }\end{array}$ & Artigo \\
\hline \multirow{3}{*}{$\begin{array}{l}\text { Atitudes no } \\
\text { bloco } \\
\text { números e } \\
\text { operações }\end{array}$} & Utsumi & 2000 & $\begin{array}{l}\text { Atitudes e habilidades } \\
\text { envolvidas na solução de } \\
\text { problemas algébricos: um } \\
\text { estudo sobre o gênero, a } \\
\text { estabilidade das atitudes e } \\
\text { alguns componentes da } \\
\text { habilidade matemática }\end{array}$ & Tese \\
\hline & $\begin{array}{c}\text { Mendes, Refosco e } \\
\text { Rogovski }\end{array}$ & 2004 & $\begin{array}{c}\text { As atitudes em relação à } \\
\text { Matemática e o desempenho } \\
\text { matemático e algébrico na } \\
\text { educação de jovens e adultos }\end{array}$ & Artigo \\
\hline & Justulin e Pirola & 2008 & $\begin{array}{l}\text { Um estudo sobre as relações } \\
\text { entre as atitudes em relação à } \\
\text { Matemática e a resolução de } \\
\text { problemas envolvendo frações }\end{array}$ & Artigo \\
\hline \multirow{3}{*}{$\begin{array}{l}\text { Atitudes no } \\
\text { bloco espaço } \\
\text { e forma }\end{array}$} & Viana & 2004 & $\begin{array}{l}\text { As atitudes de alunos do } \\
\text { ensino médio em relação à } \\
\text { geometria: adaptação e } \\
\text { validação de escala }\end{array}$ & Artigo \\
\hline & Arrebola e Jesus & 2006 & $\begin{array}{l}\text { Análise do desempenho em } \\
\text { geometria e das atitudes em } \\
\text { relação à Matemática de } \\
\text { alunos do ensino médio }\end{array}$ & Artigo \\
\hline & Venâncio e Viana & 2010 & $\begin{array}{c}\text { Atitudes em relação à } \\
\text { geometria de alunos do curso } \\
\text { de pedagogia }\end{array}$ & Artigo \\
\hline \multirow{3}{*}{$\begin{array}{l}\text { Atitudes no } \\
\text { bloco } \\
\text { tratamento da } \\
\text { informação }\end{array}$} & Vendramini & 2000 & $\begin{array}{l}\text { Implicações das atitudes e das } \\
\text { habilidades matemáticas na } \\
\text { aprendizagem dos conceitos de } \\
\text { estatística } \\
\end{array}$ & Tese \\
\hline & Berlikowski & 2012 & $\begin{array}{c}\text { Análise das atitudes e imagem } \\
\text { em relação à estatística: um } \\
\text { estudo comparativo com } \\
\text { alunos da graduação }\end{array}$ & Dissertação \\
\hline & Silva e Silva & 2013 & $\begin{array}{l}\text { Fatores determinantes de } \\
\text { mudanças de atitudes em } \\
\text { relação à estatística: um estudo } \\
\text { longitudinal com alunos de } \\
\text { Psicologia }\end{array}$ & Artigo \\
\hline
\end{tabular}

Fonte: Pesquisa bibliográfica (2016).

Por meio da categorização acima, realizamos a análise por categoria, que como já mencionamos, reuniu estudos que tiveram focos similares para podermos analisá-los de forma mais detalhada, conforme podemos visualizar a seguir.

\section{RESUltados E ANÁLISE}

Nesta seção são apresentados os resultados e as análises dos trabalhos de cada uma das quatro categorias que elaboramos. 


\subsection{ESTUDOS SOBRE ATITUDES EM RELAÇÃO À MATEMÁTICA DE UM MODO GERAL}

Brito (1996) fez uma pesquisa descritiva e correlacional, que objetivou verificar a existência e ocorrência de atitudes em relação à Matemática e a direção que estas assumem positivas ou negativas - com a finalidade de estabelecer relações entre essas atitudes e algumas variáveis selecionadas, tais como: idade; sexo; série; grau; hábitos de estudo; reprovação e compreensão dos conteúdos matemáticos, para isso utilizou uma escala de atitudes elaborada por Aiken e revisada por Aiken e Dreger em 1963 e um questionário socioeconômico para conhecer as características dos sujeitos analisados.

Outra finalidade foi permitir a melhora das condições de ensino-aprendizagem Matemática e, como consequência, aprimorar o desempenho dos alunos na disciplina, gerando condições para a ocorrência da aprendizagem significativa dos conteúdos matemáticos. Vale ressaltar que a autora não disserta sobre a aprendizagem significativa em seu texto.

Da pesquisa participaram 2007 estudantes, dos atuais ensinos fundamental ( $4^{\circ}$ a $9^{\circ}$ ano) e médio, de quatro escolas públicas e urbanas de Campinas, Paulínia e Sumaré. Eles foram agrupados quanto ao período que estudam: manhã e tarde unidos (diurno) e noturno para assim, poder anular uma excessiva dispersão de sujeitos.

Dessa forma, os resultados obtidos, permitiram a autora concluir que pelo menos para os sujeitos da pesquisa há uma correspondência entre o desempenho dos mesmos e as atitudes em relação à Matemática. Os alunos que compreendem as explicações do professor e os problemas matemáticos apresentam atitudes positivas, destacando-se em relação aos que não compreendem, não podendo assim, ser afirmado que a Matemática é a disciplina a qual os estudantes mais abominam e apresentam atitudes negativas. Pois, aparentemente essas atitudes se desenvolvem ao longo da vida escolar, sendo associados a aspectos como: o método utilizado, o docente, a autopercepção de desempenho, entre outros. É importante ressaltar que as atitudes negativas existentes ocorrem mais na $7^{\mathrm{a}}$ e $8^{\mathrm{a}}$ séries, onde principalmente a álgebra exige uma capacidade de abstração maior dos estudantes.

Araújo (1999) objetivou investigar a existência de relações entre a escolha profissional e as habilidades e atitudes em relação à Matemática. Além disso, investigou o modo como os alunos de diferentes níveis de habilidade Matemática, das áreas de exatas, biológicas e humanas resolviam problemas algébricos. Os participantes da pesquisa foram 145 alunos concluintes do ensino médio de duas escolas - uma pública e uma particular e 233 universitários. 
Para a produção das informações os instrumentos utilizados foram os seguintes: questionário, escala de atitude, teste composto por 10 questões gerais de álgebra e uma série de problemas algébricos (questões contextualizadas).

Após análise dos dados obtidos a autora concluiu que há diferenças no desempenho entre as áreas, sendo que a de exatas foi melhor que as outras. O desempenho da escola particular foi melhor que o da pública, porém nesta, o total de estudantes com atitudes favoráveis em relação à Matemática foi maior. A atitude em relação à Matemática foi mais positiva para os sujeitos de exatas, nos dois níveis. A autopercepção de desempenho apontou forte relação com o desempenho e com a atitude em relação à Matemática, dentre as variáveis analisadas.

No que tange ao processo de solução de problemas, alguns discentes erraram por dificuldades existentes na própria álgebra, em nível conceitual e pela utilização incorreta de propriedades ou operações, isso mostra para Araújo (1999) a necessidade de uma metodologia que procure tornar o ensino da álgebra mais significativo para todas as pessoas, independentemente da sua escolha profissional.

Ferreira e Wodewotzki (2007) tiveram como finalidade compreender e analisar a participação dos alunos, tanto no sentido pedagógico quanto sociológico, por terem utilizado como estratégia pedagógica a Modelagem Matemática no contexto ambiental, além disso, elas objetivaram investigar e estabelecer relações com as atitudes desses alunos em relação à Matemática.

Como instrumentos elas utilizaram: escala de atitudes apenas para um caráter exploratório; observações diversas, dois questionários e entrevistas. Optando pela pesquisa qualitativa. Sendo que os participantes do estudo foram alunos da $3^{\text {a }}$ série do ensino médio de uma escola pública (a turma era composta por 41 alunos, sendo 22 do sexo feminino e 19 do sexo masculino), o professor de Matemática da classe e uma aluna do último ano de graduação de Licenciatura em Matemática da Universidade Estadual Paulista (UNESP) - Júlio de Mesquita Filho do Campus de Rio Claro, que atuava como monitora durante as atividades.

Vale ressaltar que a escala de atitudes em relação à Matemática (EARM) foi aplicada ao final do período letivo, somente para 22 alunos dessa classe, pois os alunos já haviam realizado a prova de Matemática e deixaram de ir às aulas. A maioria dos estudantes tinha 17, 18 e 19 anos.

As autoras concluíram que os alunos não têm o hábito de validar as suas soluções, o que se justifica porque geralmente as atividades rotineiras em sala de aula contemplam situações 
imaginárias. Além disso, por meio dos comportamentos deles foi possível observar que as atividades proporcionaram a necessidade de introduzir novos hábitos e atitudes em relação ao meio ambiente.

Com relação à análise das entrevistas e as observações feitas no desenrolar das atividades, elas perceberam que as respostas dos alunos na escala de atitudes foram provavelmente influenciadas pela situação que eles vivenciaram na sala de aula de Matemática durante a sua trajetória. Discentes que apresentaram sérios problemas de aprendizagem conseguiram vencer suas dificuldades em vários conteúdos matemáticos, tomar iniciativas, ampliar a consciência crítica por meio da investigação e reflexão.

Brito, Faria e Moro (2008) realizaram um estudo com o propósito de comparar a existência e a direção da atitude em relação à Matemática de quatro grupos amostrais: estudantes de Licenciatura em Matemática em dois momentos de sua formação (alunos de início e fim da licenciatura), e professores de Matemática em dois momentos do exercício profissional (professores do início e fim da carreira), para assim, verificar as possíveis transformações de suas atitudes, durante esses momentos, bem como identificar os componentes característicos de ordem qualitativa dessa variável.

A pesquisa foi executada com a participação de 440 voluntários de instituições escolares escolhidas por conveniência e caracteriza-se com uma investigação não-experimental, sendo primordialmente comparativa. Os instrumentos utilizados foram: escala de atitude, texto autobiográfico (sobre seus vínculos com o campo do conhecimento - a Matemática), questionário para saber o perfil dos participantes de cada grupo amostral (exemplo: gênero, faixa etária, formação escolar, experiência profissional, entre outros) e entrevista semiestruturada.

Para os autores, a análise dos dados ocorreu de forma qualitativa e quantitativa, isso os permitiu obter os resultados a seguir: 1) constatar diferenças na medida de atitudes em relação à Matemática entre os grupos amostrais, sendo expressiva a presença de atitude favorável de alunos do início da licenciatura em comparação à de professores em exercício; 2) essas diferenças foram comprovadas por traços característicos dos tipos de atitude, identificados por análise qualitativa; 3) a mudança de atitude em relação à Matemática pode ser explicada pelas particularidades das diferentes circunstâncias da vida estudantil e profissional.

Ferreira e Torisu (2009) tiveram como objetivo identificar as atitudes e o autoconceito em relação à Matemática de 464 estudantes de $5^{\circ}$ e $7^{\circ}$ anos de Ouro Branco (MG). Para isso, utilizaram como instrumentos de pesquisa duas escalas do tipo Likert e um questionário. 
Os autores mostraram que, ao contrário da crença dominante, a maioria dos alunos do estudo afirma gostar de Matemática. Além disso, não se encontraram diferenças significativas entre atitudes e autoconceito, quando se compara alunos de $4^{\mathrm{a}}$ e $6^{\mathrm{a}}$ séries. Por meio da análise estatística eles verificaram que discentes do sexo feminino, de ambas as séries, têm atitudes e autoconceito mais favoráveis em relação à Matemática e que o autoconceito, no grupo observado, influencia as atitudes dos alunos em relação à Matemática.

O artigo de Descovi, Marmitt e Soares (2010) visou a modificação de concepções e atitudes negativas em relação à Matemática por meio da aplicação de atividades utilizando a resolução de problemas. Os sujeitos pesquisados foram 160 alunos do oitavo ano do ensino fundamental, estudantes da rede municipal de Três Coroas, Rio Grande do Sul, bem como sete professores da área da Matemática do município. No texto estão relatados os resultados da pesquisa aplicada a duas turmas, com o total de 36 alunos do oitavo ano fundamental.

As autoras realizaram uma análise qualitativa dos resultados, buscando identificar os aspectos nos quais as concepções negativas estavam focadas, juntamente com a aplicação de escalas de atitudes analisadas quantitativamente por meio do software estatístico SPSS (Statistical Package for Social Science), versão 11.5 para Windows e o nível de significância adotado foi de 0,05 . Os dados foram analisados por meio do teste t de Student para amostras pareadas.

Elas concluíram que a Matemática se torna uma disciplina de grande dificuldade por meio das experiências já vividas pelos alunos, e que experiências positivas podem modificar esta visão, por meio de uma metodologia diferenciada utilizada pelo professor, melhorando assim as atitudes e concepções por eles apresentadas.

Uma vez que, apesar das atitudes dos discentes terem modificado positivamente, as concepções mais "enraizadas" a respeito da Matemática ainda não foram modificadas. Continuaram indicando que o rigor da resolução nessa disciplina, determina o sucesso e o fracasso do aluno, que é avaliado em provas, as quais deve repetir o modelo apresentado pelo professor para poder obter boas notas e ser aprovado ao final do ano letivo.

Jesus e Tacacima (2012) pesquisaram 809 alunos do $1^{\circ}$ ano do curso de Engenharia, os quais 698 cursavam a disciplina de Cálculo Diferencial e Integral I, pela primeira vez, enquanto que 111 discentes cursavam pela segunda vez a disciplina, pois faziam dependência. Eles tiveram como objetivo analisar as relações entre as atitudes em relação à Matemática e o desempenho em Cálculo Diferencial e Integral I de alunos que cursam Engenharia. 
Para isso, foi utilizada a mesma escala de atitudes em relação à Matemática mencionada nos estudos anteriormente citados. Para análise das relações entre atitudes e desempenho foram consideradas as variáveis: pontuação na Escala de Atitudes e a média de desempenho em Cálculo Diferencial e Integral I de cada aluno. O modelo seguido pela pesquisa foi o quantitativo explicativo, com uma análise quantitativa das variáveis.

Segundo os autores da pesquisa, os resultados apresentados nos testes t-Student, contribuíram para fortalecer a ideia de que os professores de Matemática devem compreender pontos referentes ao processo ensino-aprendizagem, sobre relações entre atitude e o desempenho em uma atividade acadêmica, e questões como: inteligência; motivação e relações interpessoais, que podem influenciar o trabalho na sala de aula.

A pesquisa de Costa e Costa (2013) teve como objetivo investigar associações entre as atitudes em relação à Matemática e o desempenho na disciplina de alunos do $6^{\circ}$ ano do ensino fundamental de uma escola da rede pública de ensino do município de Caririaçu, interior do Ceará. Para isso, 37 alunos com idades entre 10 e 14 anos participaram desse estudo.

O estudo é identificado como uma pesquisa descritiva correlacional, transversal, quantitativa, observacional e de campo. O instrumento utilizado foi a EARM elaborada por Aiken e adaptada por Brito (1996) com a finalidade de avaliar as atitudes dos discentes em relação à disciplina. Essa escala foi composta por vinte questões, sendo dez afirmações positivas e dez negativas, além de uma questão para o sujeito avaliar o seu desempenho em relação à Matemática. Vale salientar que o desempenho na disciplina mencionada foi averiguado a partir da média das notas dos três primeiros bimestres.

Assim, obtiveram os seguintes resultados: 1) as meninas apresentaram médias superiores aos meninos tanto na EARM quanto no desempenho escolar; 2) 94,6\% dos participantes da amostra consideraram a Matemática interessante e disseram que gostam da disciplina; 3) 86,5\% dos alunos que participaram da pesquisa acharam que a disciplina é fascinante e divertida, e se sentem tranquilos em relação à Matemática; 4) o teste de correlação de Spearman apontou correlação positiva e moderada, na qual os achados evidenciam uma relação positiva entre as atitudes em relação à Matemática e o desempenho escolar na disciplina.

Jesus e Testani (2016) fizeram uma pesquisa que teve como objetivo analisar as relações entre o desempenho e as atitudes de discentes que cursavam a disciplina de Cálculo Diferencial e Integral na Variável Complexa. Os sujeitos da pesquisa foram 294 alunos, matriculados no terceiro semestre de cursos de Engenharia, tais como: Mecânica, Civil, Química, Elétrica e de 
Produção. Os mesmos foram distribuídos da seguinte forma: 68 alunos do gênero feminino, 226 alunos do gênero masculino.

No estudo, o que ocorreu foi a proposta de analisar relações e desigualdades de escores entre as variáveis atitudes em relação à Matemática e desempenho. Na perspectiva cognitiva, os sujeitos foram aceitos exatamente como estavam, seguindo desta forma um modelo quantitativo explicativo.

Para o desenvolvimento da pesquisa foram utilizados os seguintes instrumentos: uma escala de atitudes em relação à Matemática do tipo Likert, revisada e elaborada por Aiken e Dreger e a prova composta por questões de Cálculo Diferencial e Integral na Variável Complexa.

A análise dos resultados produzidos permitiram os autores concluírem que adotando a significância $\alpha=0,05$, houve uma correlação fraca entre as variáveis, desempenho e atitude em relação à Matemática, $r=0,196$ e $p=0,001$. A mesma independente de ser fraca é extremamente significativa, pois indicam atitudes positivas em relação à Matemática dos alunos que cursam Engenharia, pois conforme já mencionado no estudo de Brito (1996), quando o estudante tem a autopercepção de que seu desempenho está melhorando, as atitudes dele tendem a ser favoráveis.

\subsection{ESTUDOS SOBRE ATITUDES NO BLOCO NÚMEROS E OPERAÇÕES}

Utsumi (2000) teve como primeiro objetivo verificar se as atitudes em relação à Matemática estavam relacionadas às variáveis gênero, série e desempenho, e a partir disso alcançar outra finalidade que foi investigar os seguintes componentes da habilidade Matemática: percepção, generalização, flexibilidade de pensamento, reversibilidade dos processos mentais, encurtamento de raciocínio, compreensão, raciocínio e lógica, memória Matemática e tipo de habilidade Matemática.

Para isso os sujeitos da pesquisa analisados foram 256 alunos da sexta, sétima e oitava séries do ensino fundamental, de uma escola da rede pública de ensino do Estado de São Paulo. E os instrumentos utilizados por ela na primeira fase do estudo foram: um questionário para caracterização do perfil dos alunos; uma escala de atitudes em relação à Matemática e um teste matemático.

Com a análise dos dados a autora obteve os seguintes resultados: 1) a média das atitudes em relação à Matemática foi mais baixa para os sujeitos que frequentavam a sexta série, talvez devido a problemas pedagógicos internos da escola, o que reforçou o caráter instável e, 
portanto, mutável das atitudes; 2) as variáveis: série, reprovações, hábitos de estudo, compreensão dos problemas matemáticos e autopercepção de desempenho estavam relacionadas às atitudes dos sujeitos em relação à Matemática e que as variáveis: série, reprovações, gênero, compreensão dos problemas e autopercepção de desempenho estavam relacionadas à nota dos sujeitos no teste matemático. Pois, de acordo com Utsumi (2000) foi verificado que para os sujeitos do estudo, o fato de ter ou não sido reprovado alguma vez estava relacionado tanto às suas atitudes quanto às suas notas: os que já haviam sido reprovados apresentaram atitudes mais negativas e notas mais baixas no teste matemático.

$\mathrm{Na}$ segunda fase da pesquisa foram selecionados três alunos (um de cada série) que obtiveram melhor desempenho (mostraram habilidade Matemática) para solucionarem problemas algébricos usando o mecanismo de "pensar em voz alta", com o propósito de identificar os componentes da habilidade que se evidenciavam no decorrer da solução de problemas.

A partir da investigação dos dados da segunda fase Utsumi (2000, p.07) obteve o resultado a seguir: 1) “[...] a análise dos protocolos dos sujeitos considerados mais capazes em Matemática, durante a solução de problemas algébricos, mostrou que os mesmos não eram capazes de solucionar os problemas propostos, que evidenciariam a habilidade Matemática desses sujeitos".

Mendes, Refosco e Rogovski (2004) objetivaram o seguinte: identificar a atitude em relação à Matemática de alunos da Educação de Jovens e Adultos; analisar o desempenho matemático e algébrico de alunos jovens e adultos; verificar as possíveis correlações entre a atitude em relação à Matemática e o desempenho em Matemática, e em Álgebra, desses mesmos discentes.

Os sujeitos da pesquisa foram 85 alunos concluintes do ensino fundamental, em Matemática, de uma Escola de Jovens e Adultos, localizada na região Oeste do Estado do Paraná, matriculados nas modalidades de atendimento individual e coletivo.

Os instrumentos utilizados para a pesquisa foram: um questionário com a finalidade de obter informações pessoais dos entrevistados; e de acordo com Mendes, Refosco e Rogovski, (2004, p.10) “a escala de atitudes em relação à Matemática traduzida, adaptada e validada por Brito (1996, 1998) e é do tipo Likert com 20 proposições (10 positivas e 10 negativas), que tentam expressar o sentimento que cada indivíduo possui em relação à Matemática”.

As análises dos resultados permitiu às autoras concluírem que os alunos da Educação de Jovens e Adultos (EJA) investigados gostam de Matemática, visto que foi encontrada uma 
atitude positiva dos sujeitos em relação a ela; portanto, para os sujeitos desta pesquisa, os resultados contradizem a ideia divulgada, na informalidade, que os alunos de EJA não apreciam esta disciplina.

No que concerne ao desempenho, a análise dos dados mostrou que existe uma forte correspondência entre desempenho em Matemática e o desempenho em Álgebra, o que permite Mendes, Refosco e Rogovski (2004) afirmarem que, para este grupo, quanto maior o desempenho em Álgebra melhor o desempenho em Matemática.

Já, nas relações do desempenho com a atitude elas verificaram que, para a amostra pesquisada, os resultados encontrados indicaram que a atitude em relação à Matemática está diretamente relacionada tanto ao desempenho em Matemática como ao desempenho em Álgebra, na Educação de Jovens e Adultos. Consequentemente, quanto melhor o desempenho em Álgebra, ou em Matemática, melhor a atitude em relação à Matemática. Porém, quando as autoras compararam os dados da relação da atitude com o desempenho em Álgebra e em Matemática, apareceu uma correlação mais forte entre a atitude e o desempenho em Matemática do que entre a atitude e o desempenho em Álgebra.

Justulin e Pirola (2008) objetivaram investigar as possíveis relações entre as atitudes em relação à Matemática e a resolução de problemas envolvendo frações. A pesquisa foi realizada com 95 estudantes do ensino médio de uma escola pública estadual de uma cidade da Diretoria de Ensino - Região Jaú, distribuídos da seguinte forma: 32 discentes do $1^{\circ}$ ano, 37 do $2^{\circ}$ ano e 26 do $3^{\circ}$ ano, todos do período da manhã.

Os instrumentos utilizados foram os seguintes: questionário pessoal, escala de atitudes em relação à Matemática, prova de Matemática a ser realizada por meio do recurso Mínimo Múltiplo Comum (M.M.C), prova de Matemática para resolver operações com frações sem utilizar o M.M.C e entrevista audiografada.

Como resultado, referente às atitudes em relação à Matemática, eles perceberam que em média os alunos do $3^{\circ}$ ano gostam menos de Matemática do que os alunos do $1^{\circ} \mathrm{e} 2^{\circ}$ anos e, que as meninas iniciam gostando mais que os meninos da disciplina no $1^{\circ}$ ano e no $3^{\circ}$ ano elas gostam menos que os meninos. Em relação ao desempenho na prova de Matemática os alunos apresentaram melhor desempenho na prova de algoritmo, do que na prova que contém os problemas. Por fim, a relação entre as atitudes e o desempenho na prova de Matemática mostrou de forma separada que há uma relação dessas variáveis por série, e mais tenuemente com gênero. 
Contudo, ao se analisarem essa correlação por série os autores observaram uma correlação mais forte e relativamente diferenciada por gênero. De maneira geral, perceberam que a correlação geral entre essas variáveis foi muito baixa, embora significativa.

\subsection{ESTUDOS SOBRE ATITUDES NO BLOCO ESPAÇO E FORMA}

Viana (2004) buscou relações entre as atitudes em relação à Matemática e à geometria, já que a experiência observada em outros trabalhos analisados tem mostrado que vários alunos demonstram sentimentos distintos em relação a essas disciplinas.

O trabalho foi realizado com 423 estudantes do ensino médio de três escolas particulares e uma escola da rede estadual paulista. Para análise do mesmo, foram utilizados os seguintes instrumentos: escala de atitudes em relação à Geometria (EARG) que foi adaptada da escala de atitudes em relação à Matemática (EARM) do tipo Likert, a qual foi elaborada e revisada por Aiken e Dreger (1961).

Para Viana (2004), a análise da correlação entre a EARM e a EARG foi positiva moderada, ou seja, "[...] os sujeitos que tinham as atitudes mais negativas em relação à matemática também tenderam a ter as atitudes mais negativas em relação à geometria. Os alunos com atitudes mais positivas em relação à matemática também tenderam a ter as atitudes mais positivas em relação à geometria" (p.16-7).

O trabalho de Arrebola e Jesus (2006) teve o objetivo de analisar o desempenho em geometria e atitudes em relação à Matemática de alunos do ensino público e privado. Para isso, os participantes da pesquisa foram aproximadamente 150 alunos de ambos os gêneros, regularmente matriculados no $1^{\circ}$ ano do ensino médio, com idades entre 14 e 16 anos, em escolas localizadas na cidade de Santos, localizada no Estado de São Paulo. E os instrumentos utilizados pelos autores foram: uma prova de Matemática, composta por 10 (dez) questões de geometria e uma escala de atitudes em relação à Matemática do tipo Likert.

Arrebola e Jesus (2006) concluíram que os testes mostraram que o desempenho dos sujeitos em geometria e as atitudes em relação à Matemática estavam correlacionados positivamente, coeficiente $r=0,614$.

Quando foram comparados resultados de desempenho na prova de geometria percebeuse que houve diferença significativa entre os sujeitos da escola pública e privada $(p<0,05)$. No que tange às atitudes em relação à Matemática também foram encontrados diferença de resultados, todavia não significativos $(p>0,05)$. 
Venâncio e Viana (2010) objetivaram levantar no artigo por eles elaborado, as atitudes em relação à geometria de futuros professores das séries iniciais do ensino fundamental. Para isso, investigaram 87 discentes, dos turnos diurno e noturno, dos $1^{\circ}$ e $3^{\circ}$ períodos do Curso de Pedagogia da Faculdade de Ciências Integradas do Pontal pertencente à Universidade Federal de Uberlândia (FACIP/UFU), os quais foram analisados mediante uma escala de atitudes em relação à geometria.

A partir da análise realizada, os autores concluíram que os estudantes têm uma atitude pouco favorável em relação à geometria e que existe uma correspondência entre autopercepção do desempenho e atitudes, apontando que os sentimentos são influenciados pela sensação de sucesso ou fracasso na disciplina matemática.

\subsection{ESTUDOS SOBRE ATITUDES NO BLOCO TRATAMENTO DA INFORMAÇÃO}

Vendramini (2000) realizou uma pesquisa que objetivou investigar as relações entre as atitudes em relação à Estatística, as habilidades matemáticas e a aprendizagem dos conceitos estatísticos, na qual os sujeitos participantes foram 319 alunos de uma universidade particular do interior do Estado de São Paulo. As informações foram geradas por meio dos seguintes instrumentos: um questionário informativo, uma escala de atitudes em relação à Estatística, uma prova de Estatística e uma prova de Matemática.

As conclusões da autora foram as seguintes: (1) nas relações entre as variáveis estudadas não houve diferenças expressivas das atitudes em relação à Estatística entre os sujeitos que conseguiram identificar características do conceito da disciplina e aqueles que não conseguiram realizar essa identificação e que a porcentagem de sujeitos com atitudes positivas foi superior aos de atitudes negativas, que mencionaram pelo menos uma utilidade para a Estatística; (2) a análise das correlações entre o desempenho dos sujeitos em Estatística, a atitude em relação à Estatística, o desempenho na prova de Estatística e de Matemática, mostrou associações positivas; (3) a análise de regressão múltipla apontou que, quanto mais positiva eram as atitudes dos estudantes em relação à Estatística e quanto melhor o desempenho na solução de problemas matemáticos, melhor era o desempenho deles em Estatística.

Para Vendramini (2000) esses resultados propõem que sejam adotadas estratégias de ensino que desenvolvam as habilidades matemáticas e que tornem as atitudes em relação à Estatística mais positiva. Além disso, os resultados também mostraram que os alunos manifestaram atitudes positivas na maioria dos grupos estudados, principalmente, no que se refere ao grupo de sujeitos os quais as mães estudaram até o nível superior; os grupos que 
estavam cursando a segunda série e aqueles com autopercepção de um bom desempenho em Estatística.

O estudo de Berlikowski (2012) objetivou analisar a imagem e as atitudes que os alunos de cursos superiores de uma faculdade particular apresentam em relação à Estatística, por meio de um estudo comparativo antes e depois de cursarem a disciplina.

Para a realização da pesquisa os instrumentos foram aplicados em duas etapas: questões de múltipla escolha, nas quais os discentes manifestaram suas opiniões sobre a imagem e às atitudes em relação à Estatística; e a segunda parte, questionário do aluno, com a finalidade de levantar informações gerais e sócio demográficas dos alunos.

A autora aplicou um total de 192 questionários com os alunos dos cursos de graduação em Administração, Sistemas de Informação e Ciências Contábeis de uma Instituição de Ensino Superior (IES), localizada na Região Metropolitana de Porto Alegre, na cidade de Gravataí. Sendo importante ressaltar que o estudo foi longitudinal, já que foram descartados, na segunda aplicação do questionário, alguns estudantes que desistiram de cursar a disciplina ou cancelaram a matrícula. Os dados dos questionários foram analisados pela Escala de Atitudes em relação à Estatística (EAE) e submetidos à análise de fatores, com isso, foi observado pela autora que a escala apresentou boa consistência interna no segundo questionário, com Alpha de Cronbach de 0,86.

Berlikowski (2012) fez uma análise Estatística Descritiva dos dados e apresentou os seguintes resultados: (1) A análise fatorial exploratória identificou três fatores subjacentes baseados na escala original para a discussão dos resultados: autoconfiança/afeto/segurança, importância/aplicabilidade e utilidade/habilidade; (2) Comparando-se as atitudes e a imagem que os alunos possuem em relação à Estatística antes e depois de cursarem a disciplina, verificou-se que os estudantes ora tiveram atitudes e imagem favoráveis ora desfavoráveis. A autora levantou a suposição de que a oscilação das atitudes esteja ligada a outros fatores não contemplados por esse estudo, como: metodologia do professor, dificuldade de aprendizagem, ambiente de sala de aula, etc. Mesmo com este tipo de comportamento, os alunos reconhecem a aplicabilidade dos conhecimentos estatísticos.

Diante disso a autora concluiu que: 1) De forma geral, os resultados das análises dos dados dos dois questionários apontaram um pequeno aumento na média das questões que demonstraram as atitudes positivas dos alunos, levando-se a crer que diante do contexto, que os alunos apresentaram atitudes mais favoráveis em relação à Estatística no final do semestre; 2) Os resultados mostraram que a Escala de Atitudes em relação à Estatística, pode ser utilizada 
pelos professores como um instrumento para verificar quais fatores podem estar interferindo no entendimento dos alunos em relação aos conceitos estatísticos, possibilitando ao professor traçar novas metodologias para uma aprendizagem mais significativa.

O estudo de (SILVA, V.; SILVA, C., 2013) objetivou detectar fatores que provocam mudanças de atitudes em relação à Estatística e os fatores responsáveis pela estabilidade dessas. A pesquisa foi realizada com todos os alunos de Psicologia da Universidade São Judas Tadeu em São Paulo, que estavam matriculados na disciplina de Estatística no início de 2009, no final de 2009 e no terceiro ano de Psicologia, final de 2011, respectivamente. E ocorreu em quatro momentos, sendo definida como uma investigação longitudinal.

As informações foram produzidas por meio da aplicação de dois questionários, da realização de uma entrevista semiestruturada e aplicação de duas escalas de atitudes em relação à Estatística: Escalas de Atitudes em Relação à Estatística (EAEc) e Survey of Attitudes Towards Statistics (SATS), ambas do tipo Likert, as quais foram respondidas pelos participantes e seus dados quantitativos examinados com a utilização do software SPSS (versão 12.0) e a análise de conteúdo foi empregada para interpretar os resultados das entrevistas.

As conclusões obtidas pelas pesquisadoras foram as seguintes: (1) as atitudes não sofreram alteração com o ganho de conhecimento de conceitos estatísticos obtidos na disciplina, mas as atitudes foram mais positivas após a aplicação da Estatística em projetos de pesquisa; (2) aos fatores desencadeadores de mudança das atitudes negativas para positivas constatou-se o relacionamento em sala e as notas como responsáveis; (3) à mudança de atitudes positivas para negativas, atribuiu-se a demanda de estudo e prática dos exercícios.

Portanto, de acordo com as autoras no decorrer de dois anos do final da disciplina Estatística foi fundamental para que houvesse uma mudança expressiva das atitudes para positivas e o convívio saudável e produtivo com colegas e professores também foram fatores apontados como determinantes das atitudes positivas.

\section{CONSIDERAÇÕES FINAIS}

Os estudos em Educação Matemática são de extrema relevância para gerar reflexões necessárias sobre o processo de ensino e aprendizagem nas salas aulas, seja da Educação Básica, seja do ensino superior. Afinal resultados de pesquisas podem ser indicadores de mudanças de posturas necessárias para melhoria de práticas docentes, processos metodológicos e, sobretudo, de revisão das relações de professores e alunos nos contextos das aulas de Matemática. Consciente da necessidade do controle didático dos vários fatores, citados acima, que 
favorecem e facilitam o ensino e a aprendizagem, certamente serão visíveis mudanças de atitudes discentes em relação ao gostar, seja da disciplina Matemática, seja de outras disciplinas do currículo.

Ao finalizar este trabalho que se propôs a apresentar resultados de investigações realizadas referentes às atitudes em relação à Matemática e em alguns blocos de conteúdos dos PCN, observamos que essas estão relacionadas à compreensão dos alunos sobre os conteúdos abordados nas aulas, ao método utilizado pelos professores para ensinar, à percepção dos discentes no seu próprio desempenho, a utilização de conhecimentos matemáticos nas atividades cotidianas, entre outros.

No que se refere ao sentimento positivo ou negativo referente à disciplina Matemática, percebemos por meio dos instrumentos utilizados pelos pesquisadores em suas análises: escalas de atitudes; questionários e provas de Matemática, entre outros, que a maioria dos alunos apresenta atitudes favoráveis em relação à área de estudo e aos conteúdos que são abordados na mesma, principalmente se eles têm um bom desempenho no processo de aprendizagem, havendo correlação entre essa variável e as atitudes.

Dentre outros fatores foi possível notar que os discentes que não assimilam o que lhes é ensinado, apresentam um baixo desempenho o que pode estar associado ao sentimento de insucesso e consequentemente atitudes negativas em relação à disciplina. Além disso, percebemos que as atitudes negativas aumentam de frequência com o avanço da escolaridade e idade. Porém, para os sujeitos analisados o quantitativo que apresentou atitudes negativas não foi tão significativo em relação ao que manifestou atitudes favoráveis.

Diante do exposto, um dos fatores que pode influenciar o aprendizado de um estudante é a sua atitude, que por sua vez, pode ser modificada durante o processo de ensino e aprendizagem, sobretudo se o estudante passar a ter experiências exitosas com a Matemática e receber reforço positivo de seu professor.

Mediante os resultados dos trabalhos que constituíram base de dados para a realização dessa pesquisa podemos afirmar que a maioria dos estudantes analisados, independente dos diferentes blocos onde foram agrupados, apresenta atitudes favoráveis em relação à Matemática e aos conteúdos abordados em alguns blocos dos PCN.

\section{REFERÊNCIAS}

ARAÚJO, Elizabeth Adorno. Influências das habilidades e das atitudes em relação à matemática e a escolha profissional. 1999. 232p. Tese (Doutorado em Educação) Universidade Estadual de Campinas, Faculdade de Educação, Campinas, SP: [s.n.], 1999. 
Disponível em: http://www.repositorio.unicamp.br/handle/REPOSIP/253338. Acesso em: 15 jul. 2016.

ARREBOLA, Odilthom Elias da Silva; JESUS, Marcos Antonio Santos de. Análise do desempenho em geometria e das atitudes em relação à Matemática de alunos do ensino médio. In: ENCONTRO GAÚCHO DE EDUCAÇÃO MATEMÁTICA, 9., 2006, Caxias do Sul. Anais... Caxias do Sul, 2006. Disponível em: https://miltonborba.org/CD/Interdisciplinaridade/Encontro_Gaucho_Ed_Matem/cientificos/C C16.pdf. Acesso em: 21 ago. 2016.

BERLIKOWSKI, Márcia Elisa. Análise das atitudes e imagem em relação à estatística: um estudo comparativo com alunos da graduação. 2012. 63f. Dissertação (Mestrado em Educação em Ciências e Matemática) - Faculdade de Física, Pontifícia Universidade Católica do Rio Grande do Sul, Porto Alegre, 2012. Disponível em: http://tede2.pucrs.br/tede2/bitstream/tede/3432/1/442097.pdf. Acesso em: 19 jul. 2016.

BRASIL. Secretaria de Educação Fundamental. Parâmetros Curriculares Nacionais: Matemática - Ensino de quinta a oitava séries - Brasília: MEC / SEF, 1998. 148p. Disponível em: http://portal.mec.gov.br/seb/arquivos/pdf/matematica.pdf. Acesso em: 25 mar. 2013.

BRITO, Márcia Regina Ferreira de. Um estudo sobre as atitudes em relação à Matemática em estudantes de $\mathbf{1}^{\mathbf{0}} \mathbf{e} \mathbf{2}^{\mathbf{o}}$ graus. 1996. 383f. Tese (Livre docência) - Universidade Estadual de Campinas, Faculdade de Educação, Campinas, SP, 1996. Disponível em: http://www.repositorio.unicamp.br/handle/REPOSIP/251566. Acesso em: 16 mar. 2016.

BRITO, Márcia Regina Ferreira de; FARIA, Paulo Cézar; MORO, Maria Lucia Faria. Atitudes de professores e futuros professores em relação à Matemática. Estudos de Psicologia, 13(3), p. 257-265, 2008. Disponível em:

https://www.scielo.br/pdf/epsic/v13n3/a08v13n3.pdf. Acesso em: 16 mar. 2016.

COSTA, Cicera Vania Barros; COSTA, Cicero Luciano Alves. Desempenho e atitudes em relação à matemática de alunos do $6^{\circ}$ ano do ensino fundamental. Revista Brasileira de Ensino de Ciência e Tecnologia, v. 6, n. 3, p. 1-11, set-dez.2013. Disponível em: https://periodicos.utfpr.edu.br/rbect/article/view/1419/1148. Acesso em: 21 mar. 2016.

DESCOVI, Lucieli Martins Gonçalves; MARMITT, Vivian Regina; SOARES, Maria Ieda. Concepções e atitudes em relação à matemática: prática em busca de uma construção positiva. In: ENCONTRO NACIONAL DE EDUCAÇÃO MATEMÁTICA, 10., 2010, Salvador. Anais... Salvador, 2010. Disponível em: http://atelierdigitas.net/CDS/ENEM10/artigos/RE/T21_RE1209.pdf. Acesso em: 05 jun. 2016.

FERREIRA, Ana Cristina; TORISU, Edmilson Minoru. Atitudes e autoconceito em relação à matemática: um estudo com alunos do $5^{\circ}$ e do $7^{\circ}$ ano das escolas públicas de Ouro Branco MG. In: SEMINÁRIO INTERNACIONAL DE PESQUISA EM EDUCAÇÃO MATEMÁTICA, 4., 2009, Taguatinga-DF. Anais... Taguatinga, 2009. Disponível em: http://www.sbembrasil.org.br/files/sipemIV.pdf. Acesso em: 05 jun. 2016.

FERREIRA, Denise Helena Lombardo; WODEWOTZKI, Maria Lúcia Lorenzetti. Matemática e escala de atitudes no ensino médio: uma abordagem no contexto da pesquisa 
qualitativa. In: ENCONTRO NACIONAL DE EDUCAÇÃO MATEMÁTICA, 9., 2007, Belo Horizonte. Anais... Belo Horizonte, 2007. Disponível em:

http://sbem.iuri0094.hospedagemdesites.ws/anais/ix_enem/Html/comunicacaoCientifica.html. Acesso em: 25 nov. 2016.

JESUS, Marcos Antonio Santos de; TACACIMA, Juliana. As atitudes em relação à matemática e o desempenho em cálculo diferencial e integral de alunos de Engenharia.

Revista Ceciliana, Centro Universitário da FEI, Universidade Santa Cecília - UNISANTA Dez 4(2): 71-76, 2012. ISSN 2175-7224. Disponível em:

https://sites.unisanta.br/revistaceciliana/edicao_08/12.pdf. Acesso em: 12 abr. 2016.

JESUS, Marcos Antonio Santos de; TESTANI, Giuseppe Britto. As atitudes em relação à matemática e o desempenho em cálculo diferencial e integral na variável complexa. In: ENCONTRO NACIONAL DE EDUCAÇÃO MATEMÁTICA, 12., 2016, São Paulo. Anais... São Paulo, 2016. Disponível em: http://www.sbembrasil.org.br/enem2016/anais/pdf/5787_3122_ID.pdf. Acesso em: 15 abr. 2016.

JUSTULIN, Andresa Maria; PIROLA, Nelson Antonio. Um estudo sobre as relações entre as atitudes em relação à matemática e a resolução de problemas envolvendo frações. In:

ENCONTRO BRASILEIRO DE ESTUDANTES DE PÓS- GRADUAÇÃO EM EDUCAÇÃO MATEMÁTICA, 12., 2008, Rio Claro. Anais... Rio Claro - São Paulo: UNESP, 2008. Disponível em: http://www2.rc.unesp.br/eventos/matematica/ebrapem2008/upload/304-1-Agt3_Justulin_ta.pdf. Acesso em: 15 abr. 2016.

MENDES, Clayde Regina; REFOSCO, Marideisa Ita; ROGOVSKI, Inês. As atitudes em relação à matemática e o desempenho matemático e algébrico na educação de jovens e adultos. In: REUNIÃO ANUAL DA ASSOCIAÇÃ̃ NACIONAL DE PÓS-GRADUAÇÃO E PESQUISA EM EDUCAÇÃO (ANPEd), 27., 2004, Caxambu. Anais... Caxambu - Minas Gerais, 2004. Disponível em: http://www.anped.org.br/sites/default/files/t1910.pdf. Acesso em: 10 jun. 2016.

SILVA, Hugo Carlos Machado da. O ensino de matrizes a partir da resolução de problemas. 2016. 243f. Dissertação (Mestrado em Educação) - Universidade do Estado do Pará, 2016.

SILVA, Vanessa Ferraz da.; SILVA, Cláudia Borim da. Fatores determinantes de mudanças de atitudes em relação à estatística: um estudo longitudinal com alunos de psicologia.

Integração (USJT), ano 19, v. 1, n. 65, p. 86-90, 2013. Disponível em:

ftp://ftp.usjt.br/pub/revint/65/11_fatores_determinantes_de_mudancas_de_atitudes_em_relaca o_estatistica.pdf. Acesso em: 08 set. 2016.

UTSUMI, Miriam Cardoso. Atitudes e habilidades envolvidas na solução de problemas algébricos: um estudo sobre o gênero, a estabilidade das atitudes e alguns componentes da habilidade matemática. 246 p. Tese (Doutorado em Educação). Faculdade de Educação, Universidade Estadual de Campinas, Campinas, SP: [s.n.], 2000. Disponível em: http://repositorio.unicamp.br/bitstream/REPOSIP/251847/1/Utsumi_MiriamCardoso_D.pdf. Acesso em: 13 set. 2016. 
VENÂNCIO, Mírian Moreira Menezes; VIANA, Odaléa Aparecida. Atitudes em relação à geometria de alunos do curso de pedagogia. In: ENCONTRO NACIONAL DE EDUCAÇÃO MATEMÁTICA, 10., 2010, Salvador. Anais... Salvador, 2010. Disponível em:

http://atelierdigitas.net/CDS/ENEM10/artigos/PT/T18_PT801.pdf. Acesso em: 09 out. 2016.

VENDRAMINI, Claudette Maria Medeiros. Implicações das atitudes e das habilidades matemáticas na aprendizagem dos conceitos de Estatística. Tese (Doutorado em Educação) - Universidade Estadual de Campinas, Faculdade de Educação - Campinas, SP: [s.n.], 2000. Disponível em: https://www.psiem.fe.unicamp.br/pfpsiem/vendramini_claudettemariamedeiros_d.pdf. Acesso em: 29 abr. 2016.

VIANA, Odaléa Aparecida. As atitudes de alunos do ensino médio em relação à geometria: adaptação e validação de escala. In: ENCONTRO NACIONAL DE EDUCAÇÃO

MATEMÁTICA, 8., 2004, Recife. Anais... Recife - Pernambuco, 2004. Disponível em: http://www.sbembrasil.org.br/files/viii/pdf/03/CC00596629800.pdf. Acesso em: 18 mai. 2016.

Recebido em: 29 de julho de 2021. Aprovado em: 18 de novembro de 2021. 